\title{
POPULATION GENETIC STUDY OF RED CELL ENZYME PHOSPHOGLUCOSE ISOMERASE IN INDIA
}

\author{
Surinder S. PapiHA and Sukh M.S. ChaHAL \\ Department of Human Genetics, University of Newcastle \\ upon Tyne, England
}

\begin{abstract}
Summary The distribution of red cell enzyme phosphoglucose isomerase was studied by starch gel electrophoresis in 27 different endogamous groups of India. Forty one electrophoretic variants belonging to four out of the nine known heterozygote types and one rare homozygous variant (PGI-3) were found. Comparison of the results with in India and certain other populations showed that PGI is certainly another useful genetic parameter for the study of population diversity in Asia.
\end{abstract}

Inherited variation of the enzyme phosphoglucose isomerase [PGI; $\alpha$-D-glucose 6-phosphate ketol isomerase; EC 5.3.1.9] was initially described by Detter et al. (1968), the enzyme being referred to as phosphohexose isomerase. Since this discovery there have been reports of rare genetically determined variants or variants with low catalytic activities from various populations of the world (Baughan et al., 1968; Fitch et al., 1968; Paglia et al., 1969; Shinoda, 1970; Tariverdian et al., 1970; Welch 1971; Luan Eng and Welch, 1972; Sanpitak et al., 1973; Nakashima et al., 1973; Isacchi et al., 1979), most of which concerns the sporadic occurrence of one or two of the nine heterozygotic types originally described in addition to the usual homozygous phenotype PGI-1. The exceptions are the heterozygous phenotypes PGI 3-1 and 4-1 which are of particular interest in Asiatic populations. In both the studies from London (Detter et al., 1968; Welch, 1971) the Asiatic Indians showed an appreciable frequency of the variant PGI 3-1 and subsequent studies of indigenous samples confirmed that the $P G I^{3}$ allele attains polymorphic frequencies in certain populations of India. Indeed, the relatively high frequency of this allele led to the detection of the homozygous phenotype PGI-3 (Papiha et al., 1974).

Ishimoto and Kuwata (1974) compiled the PGI studies in Japan and showed that in Japanese PGI 4-1 variant is more frequent than the other known heterozygous variants. This relatively high frequency of the $P G I^{4}$ allele in Japan consistent with the previous studies of Shinoda (1970), also led to the finding of a rare 
homozygous phenotype PGI-4 in the Nagasaki population of Kyushu. The PGI 3-1 variant was the second most frequent found in Japan.

More recent studies of India populations have also indicated frequencies of the $P G I^{8}$ and $P G I^{5}$ alleles greater than .01 as well as the $P G I^{3}$ allele (Papiha et al., 1980; Ramesh et al., 1980). The present study extends information on the incidence and distribution of PGI alleles in 27 different endogamous groups and assesses the importance of this system in the study of population diversity in India.

\section{METHODS AND MATERIAL}

As part of the genetic studies in Indian populations, 4,618 blood specimens collected in the last 10 years were studied for PGI types in the Department of $\mathrm{Hu}$ man Genetics, Newcastle upon Tyne. The results of 2,009 samples have already been published in several surveys (Papiha et al., 1972, 1976, 1978, 1980, 1981; Papiha, 1974, 1979; Roberts et al., 1980; Chahal et al., 1982). The results on a further 2,609 subjects belonging to 27 different endogamous groups are reported here.

The hemolysates were phenotyped for PGI, using horizontal starch gel electrophoresis with Connaught hydrolysed starch. The bridge buffer consisted of $0.25 \mathrm{M}$ Tris and $0.057 \mathrm{M}$ citrate $\mathrm{pH} 8$ and the gel buffer was $0.017 \mathrm{M}$ Tris and $0.0023 \mathrm{M}$ citrate $\mathrm{pH} 8$. With Whatman No. 3. filter inserts, the electrophoresis was carried out at $10-12 \mathrm{~V} / \mathrm{cm}$ for $5 \mathrm{hr}$ at $4^{\circ} \mathrm{C}$.

Staining was carried out using fructose 6-phosphate as substrate. Certain commercial preparations contain as an impurity sufficient glucose 6-phosphate to turn the stain dark purple before the PGI zones are developed. In this case fructose 6-phosphate was prepared by the hydrolysis of fructose 1,6-diphosphate with $1 \mathrm{~N}$ $\mathrm{HCl}$. This solution is adjusted to $\mathrm{pH} 7$ before use. Fructose 6-phosphate (disodium salt) now available from Boehringer with $99.8 \%$ purity serves a practicable substrate. Fourteen $\mathrm{mg}$ substrate, $8 \mathrm{mg}$ NADP, $8 \mathrm{mg}$ MTT and $8 \mathrm{mg}$ PMS, 15 $\mu 1$ glucose 6 -phosphate dehydrogenase $(140 \mu / \mathrm{ml})$ in Tris buffer $\mathrm{pH} 8$ forms the staining mixture, which is overlaid with agar on the bottom half of the cathodal portion of the gel.

\section{RESULTS}

The distribution of phenotypes and gene frequencies in the populations now studied, and from reported surveys from India, is given in Table 1 . In a total of 8,002 subjects studied from India 80 variants of type 3-1 were found, giving an overall incidence of $1 \%$. The second most frequent variant is PGI 5-1, the 17 cases found indicating a phenotypic incidence of approximately 1 in 500 . Unlike PGI 3-1, which is distributed over all the endogamous groups, the distribution of PGI 5-1 shows affiliation to particular ethnic groups. 
a) The $P G I^{2}$ allele

The initial PGI 2-1 variant was found in a Thai individual (Detter et al., 1968). Omoto and Blake (1972) described a similar variant in a Chinese of Singapore. In the present investigation no variant of type 2-1 was found, but there are reports of one example in each of the nontribal groups of Andhra and a frequency of the $P G I^{2}$ allele of $1.2 \%$ from Christians of Kerala (Ramesh et al., 1979, 1980; Saha et al., 1976). This suggests localisation of the allele to specific populations of south India.

\section{b) The PGI allele}

Among Indian populations so far 49 occurrences of the variant PGI 3-1 have been reported, and the present investigation adds a further 31 bringing the total to eighty. As regards its overall distribution the lack of the $P G I^{3}$ allele among certain samples where a considerable number of subjects has been studied such as Kanets in Himachal Pradesh and the south Indian tribes Kolam and Chenchu suggest a genuine absence of $P G I^{3}$ allele from these populations, whereas in all the other population samples lack of the allele could well be due to small sample size. In India the $P G I^{3}$ allele frequency ranges from $.02-3.4 \%$, and 14 populations show clear polymorphic frequencies $(>1 \%)$.

In a semi-urban population from central India, Papiha et al. (1974) described the rare homozygous variant PGI-3 (genotype $P G I^{3} / P G I^{3}$ ) in addition to the usual PGI-1, and regular codominant inheritance was demonstrated by family study. In the present investigation another PGI-3 homozygote was found in a Mahajan Agarwal of Punjab (Fig. 1). This group has the highest frequency of the $P G I^{3}$ allele so far reported in the world $(3.4 \%)$.

c) The $P G I^{5}$ allele

PGI 5-1 was originally described as a Furopean variant but its occurrence in India was described initially in north India by Blake et al. (1971) and later in west-

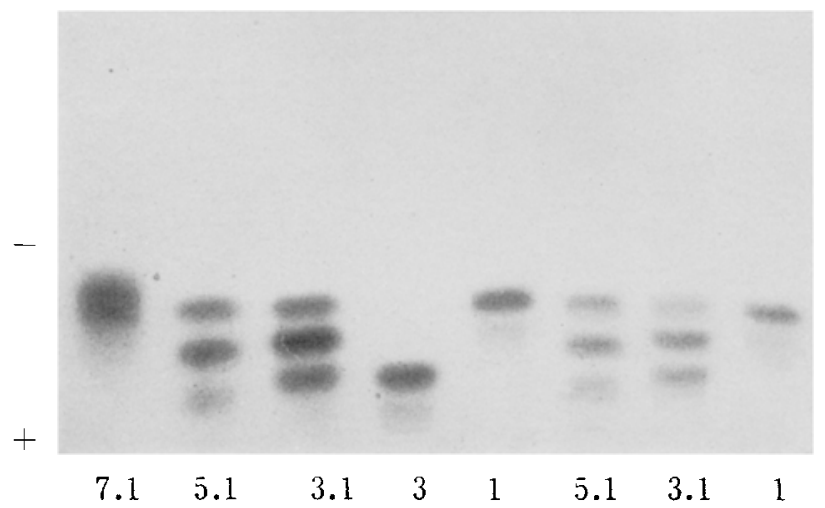

Fig. 1. Electrophoretic variants of enzyme phosphoglucose isomerase. 


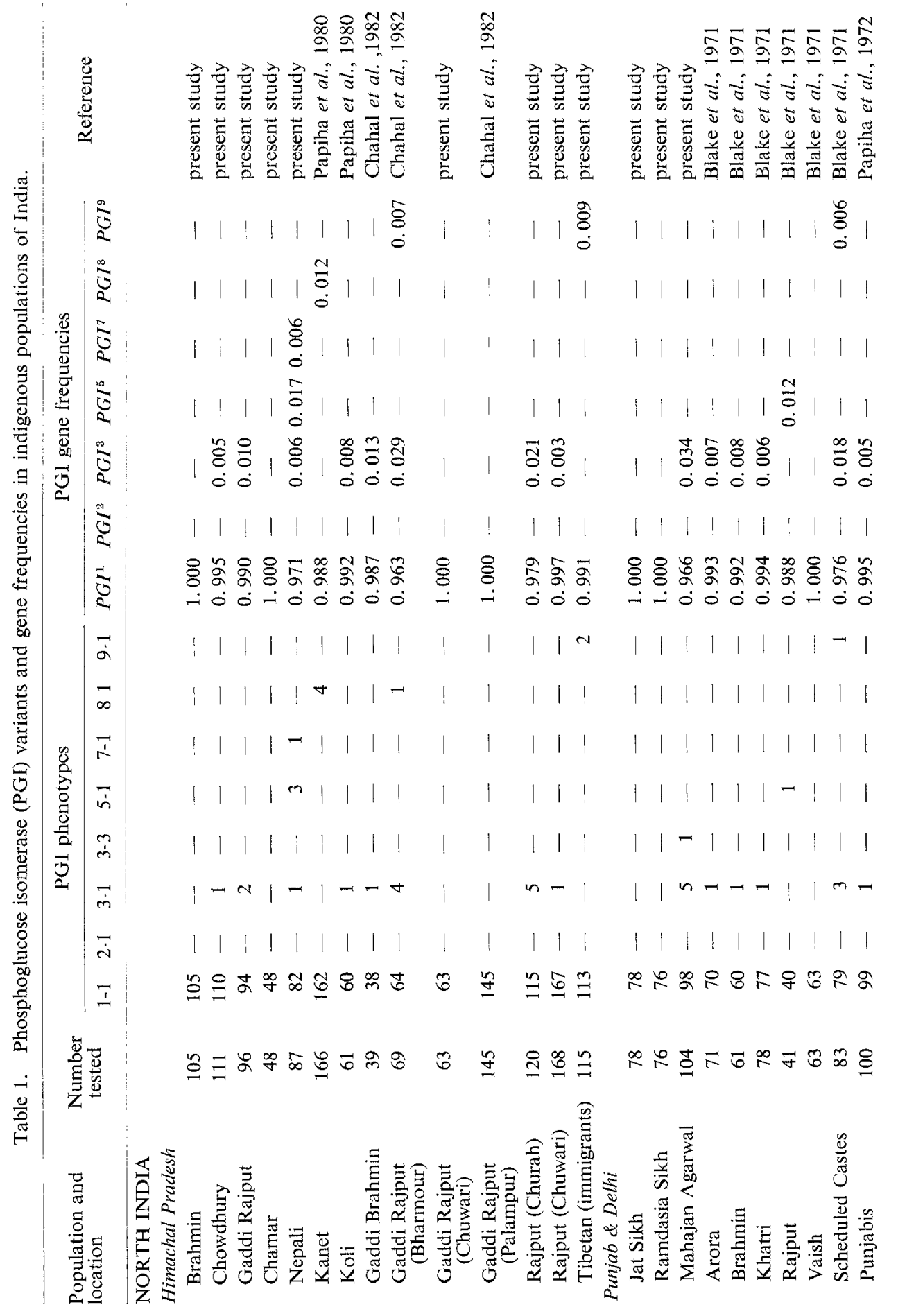


$\stackrel{0}{5} \div$

$\stackrel{\infty}{2}$

\section{$\vec{\infty} \bar{\circ} \vec{\circ} \bar{\circ}$}

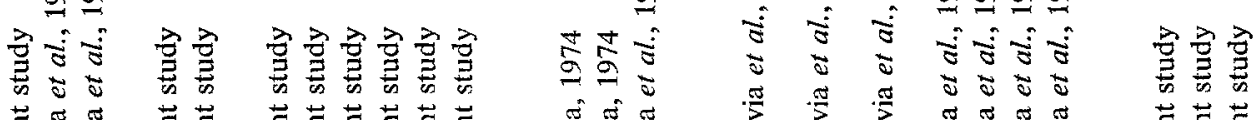

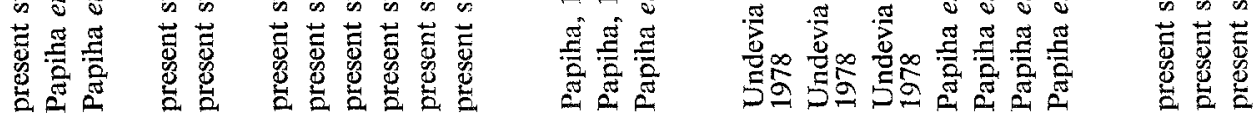
$1, \stackrel{⿱ 艹 ⿰ 氵 㔾}{0}$

$$
\begin{array}{llllll}
\mid & \mid & \mid & \mid & \mid & 1 \\
\mid & 1 & 1 & 1 & 1 & 1 \\
0 & 0 & 0 \\
0 & 0 & 0 & 0 \\
0 & 0 & 0 & 0
\end{array}
$$

$1 \quad 11 \frac{8}{8}$

$\begin{array}{lll}0 & 0 \\ 0 & 0 \\ 0 & 0 & 0 \\ 0 & 0\end{array}$

80

$\mid$\begin{tabular}{ll}
$m$ & $m$ \\
\hline & 8 \\
0 & 0 \\
0
\end{tabular}

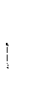

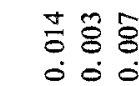

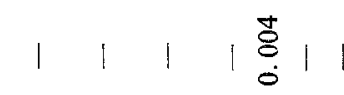

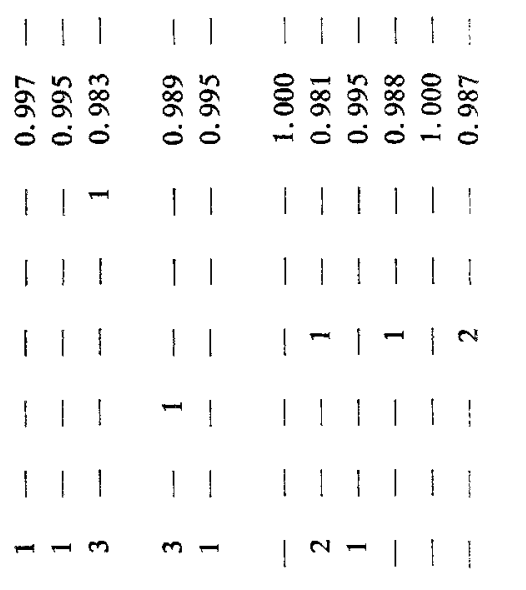

\section{1}

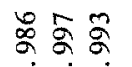

\% \%

$0 \circ \dot{0}$

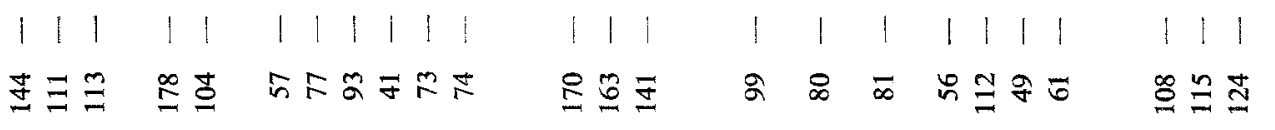

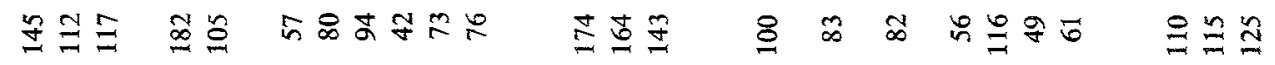

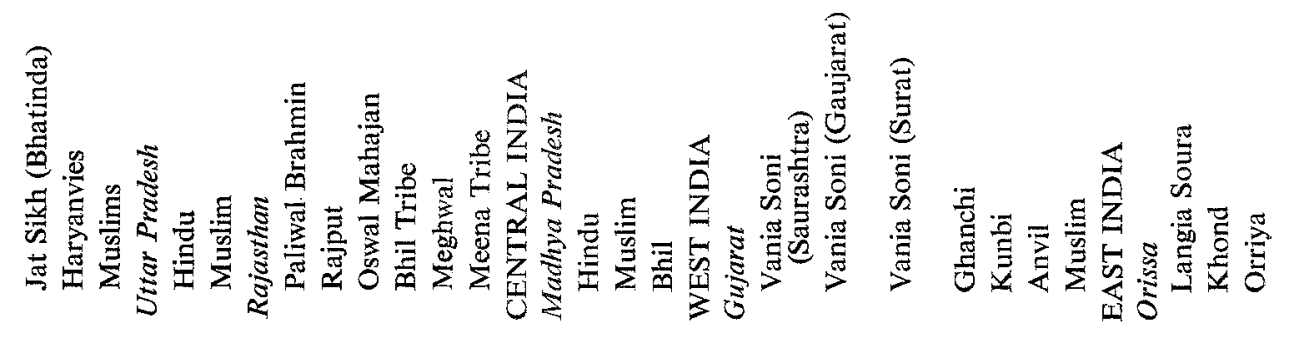
Vol. 29, No. 2, 1984 


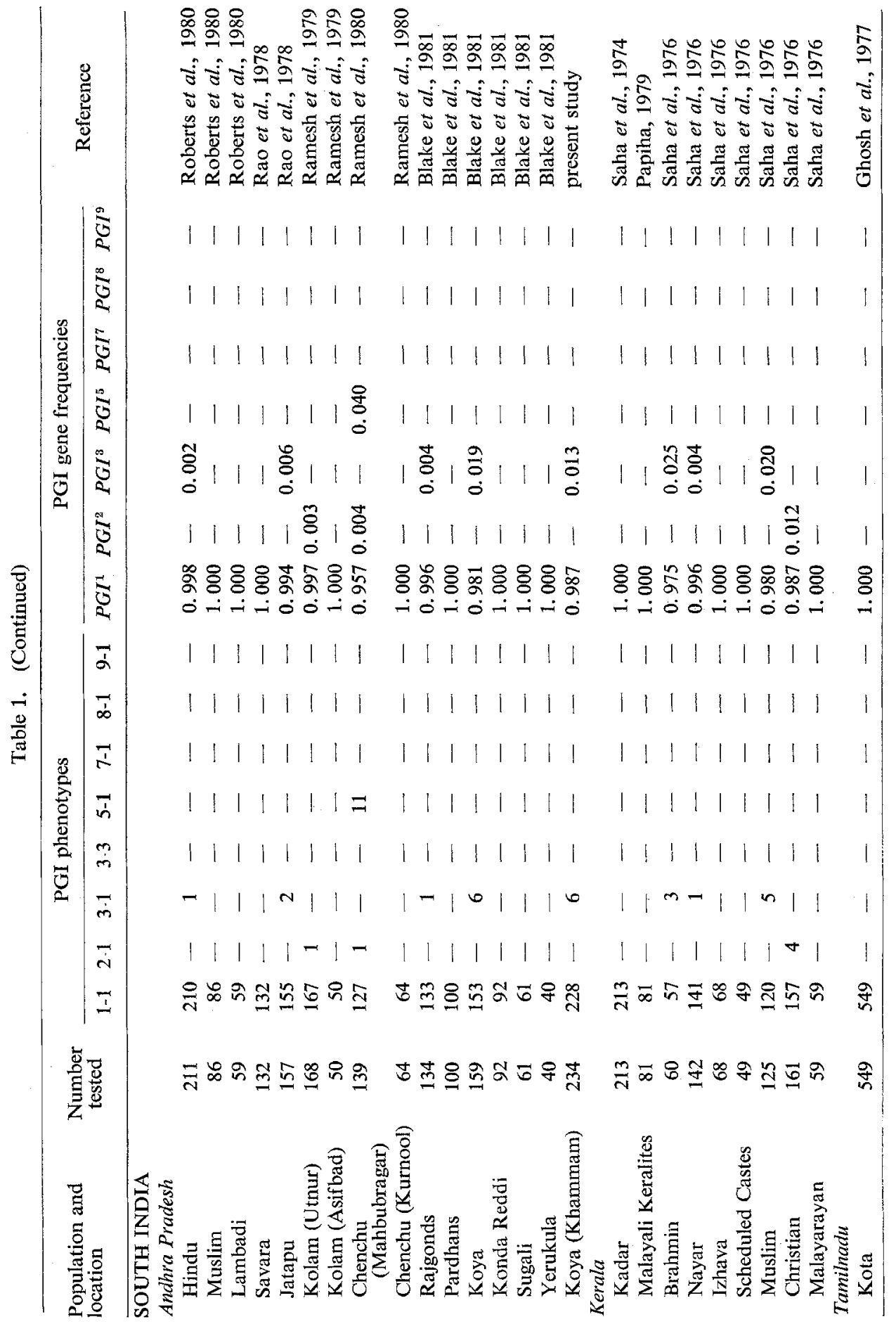


ern India. Till today 17 PGI 5-1 variants have been reported in the Indian populations. Eleven of these variants were recorded in a single south Indian tribe, the Chenchu of Mahbubnagar in the state of Andhra Pradesh, giving the highest reported $P G I^{5}$ allele frequency $(4 \%)$. Four variants of PGI 5-1 similar to that described by Omoto and Blake (1972) from the western highlands of New Guinea have been added by the present investigation (Fig. 1). Three of these variants were found in a single population, a group of Nepali, of Mongoloid affinities, who had migrated to and settled in the state of Himachal Pradesh, giving a $P G I^{5}$ allele frequency in Nepali of $1.5 \%$. The other population described with the PGI 5-1 variant is that of Japan (Shinoda, 1970), again of Mongoloid affinity. Although the $P G I^{5}$ allele was initially described in western populations, its distribution shows that the occurrence of this allele is more characteristic of the populations of the eastern hemisphere.

\section{d) The $P G I^{7}, P G I^{8}$ and $P G I^{9}$ alleles}

The electrophoretic mobility of the proteins of alleles $P G I^{7}, P G I^{8}$ and $P G I^{9}$ places them cathodally to the normal $P G I^{1}$ (Fig. 1). Six variants of type PGI 7-1 were found in the present study. Four of these phenotypes were found in the state of Rajasthan ( 3 in tribal populations and 1 in an urban group of Rajput). One phenotype each was encountered in a Nepali and an Orriya sample from the states of Himachal Pradesh and Orissa, respectively.

The variant PGI 8-1 was initially described in a Chinese individual from London. No variant of this type was found in the present samples but in our previous studies five such variants were reported from Kanet and Gaddi populations of Himachal Pradesh (Papiha et al., 1980; Chahal et al., 1982). The highest frequency of the $P G I^{8}$ allele $(1.2 \%)$ occurred in Kanets living near the Indo-Tibetan border who show considerable Mongoloid admixture (Papiha et al., 1980).

PGI 9-1 is a slightly slower variant than PGI 8-1. Three PGI 9-1 variants have already been described from the north-western states of Delhi and Gujarat (Blake et al., 1971, Papiha et al., 1976, 1978). In the present study two more variants were found in Tibetan immigrants from the state of Himachal Pradesh.

\section{DISCUSSION}

This electrophoretic investigation of PGI has shown the presence of four out of the nine known heterozygous phenotypes and one rare homozygous phenotype within the geographical region of India, occurring in a further 43 heterozygotes and one homozygote similar to those previously reported. These increased numbers allow a better appreciation of the frequencies and distribution of the PGI alleles. The population of Kanet in the northwest state of Himachal Pradesh, the south Indian tribe of Chenchu from Mahbubnagar, and Christians of Kerala have polymorphic frequencies of the $P G I^{8}, P G I^{5}$, and $P G I^{2}$ alleles, respectively. Otherwise, the $P G I^{2}$, 
$P G I^{5}, P G I^{7}, P G I^{8}$, and $P G I^{9}$ alleles are in general rare and of only sporadic occurrence in the various endogamous groups of India. The distribution of the fast alleles $P G I^{7}, P G I^{8}$ and $P G I^{9}$ not only suggests that their presence is restricted to the north-west states of India but also indicates that their occurrence characterizes the Mongoloids and populations with Mongoloid admixture such as the Kanets and some tribal populations of India. In their overall distributions these five rare alleles add considerably to the genetic diversity among the various ethnic groups of India.

The incidence and distribution of the $P G I^{3}$ allele in India also shows another interesting feature. The allele frequency exceeds $1 \%$ in a larger number of populations in north west India than in south India. The present investigation also confirms the observation of Omoto and Blake (1972). The $P G I^{3}$ allele is present in Mongoloids or populations with Mongoloid admixture, but its frequency is far lower than in the populations with Caucasoid or Dravidian affinities. The consistent distribution and wide spread occurrence of the $P G I^{3}$ allele may be attributable to the kinetic stability of protein synthesis (Tilley et al., 1974) which in the particular regional, social and biological environments may confer a selective advantage. One of the social factors which increases homoygosity is a high degree of inbreeding in certain endogamous groups of India and this confers the occurrence of the otherwise rare homozygous phenotype PGI-3, identified in this study for the second time, in this case in the Mahajan Agarwal group of Punjab.

In conclusion, the data presented in this paper clearly indicate the interest attaching to the investigation of the genetic loci controlling the isozymic variation of PGI. It is another useful indication of genetic diversity in populations of the Indian sub-continent, and the problems that this reveals, namely why do some alleles occur at polymorphic frequencies in some populations and not others will provide a fruitful topic of inquiry for some time to come.

Acknowledgements We are very grateful of Professor D.F. Roberts for his continuous help and encouragement during this work. Our thanks are also to many oversea colleagues who helped in the collection and allowed us to examine the blood samples.

\section{REFERENCES}

Baughan, M.A., Valentine, N.N., Paglia, D.E., Way, P.O., Simons, E.R., and De Marsh, Q.B. 1968. Hereditary haemotypic anemia associated with GPI deficiency. Blood 32: 236-249.

Biake, N.M., Kirk, R.L., McDermid, E.M., Omoto, K., and Ahuja, Y.R. 1971. The distribution of serum protein and enzyme group systems among North Indians. Hum. Hered. 21 : 440-457.

Blake, N.M., Ramesh, A., Vjayakumar, M., Murty, J.S., and Bhatia, K.K. 1981. Genetic studies on some tribes of Telangna region. Andhra Pradesh, India. Acta Anthropologenetica 5: 4156.

Chahal, S.M.S., Papiha, S.S., Roberts, D.F., and Singh, I.P. 1982. Serological and biochemical variation in the Gaddi tribe of Himachal Pradesh, India. Z. Morphol. Anthropol. 7: 197-208. 
Detter, J.C., Ways, P.O., Giblett, E.R., Baughan, M.A., Hopkinson, D.A., Povey S., and Harris, H. 1968. Inherited variation in human phosphohexose isomerase. Ann. Hum. Genet. $31: 329-$ 338.

Fitch, L.I., Parr, C.W., and Welch, S.G. 1968. Phosphoglucose isomerase variation in man. Biochem. J. 110: 56P.

Ghosh, A.K., Kirk, R.L., Joshi, S.R., and Bhatia H.M. 1977. A population genetic study of the Kola in Niegri Hills, South India. Hum. Hered. 27: 225-241.

Isacchi, G., Cotteau, D., Mandelli, F., Papa, G., Ciccone, F., and Kahn, A. 1979. 'GPI Roma' a new glucose phosphate isomerase deficienct variant. Hum. Genet. 46: 219-226.

Ishimoto, G. and Kuwata, M. 1974. Electrophoretic variants of red cell phosphohexose isomerase in Japan. Jap. J. Hum. Genet. 18: 356-363.

Luan Eng, L, and Welch, Q.B. 1972. Electrophoretic variants of 6 phosphoglucorate dehydrogenase (6PGD) and phosphohexose isomerase (PHI) in different racial groups in Malaysia. Hum. Hered. 22: 338-343.

Nakashima K., Miwa, S., Oda, S., Oda, E., Matsumoto, N., Fukumoto, Y., and Yamada, T. 1973. Electrophoretic and kinetic studies of glucose phosphate isomerase (GPI) in two different Japanese families with GPI deficiency. Am. J. Hum. Genet. 25: 294-301.

Omoto, K. and Blake, N.M. 1972. Distribution of genetic variants of erythrocyte phosphoglycerate kinase (PGK) and phosphohexose isomerase (PHI) among some population groups in Southeast Asia and Oceania. Ann. Hum. Genet. 36: 61-67.

Paglia, D.E., Holland, P., Baughan, M.A., and Valetine, N.N. 1969. The occurrence of defective hexosephosphate isomerase in human erythrocytes and leucocytes. New Engl. J. Med. 280: 66-71.

Papiha, S.S. 1974. Study of enzyme, protein and related polymorphisms in Man. Ph.D. Thesis, University of Newcastle upon Tyne. U.K.

Papiha, S.S. 1979. Red cell isoenzyme and serum protein types in the Malayali speaking community of Kerala, South west India. SAP, Vol. 2, Department Anthropology, Delhi Univ., pp. $1-8$.

Papiha, S.S., Roberts, D.F., Wig, N.N., and Singh, S. 1972. Red cell enzyme polymorphism in Punjabis in North India. Am. J. Phys. Anthropol, 37:293-300.

Papiha, S.S., Roberts, D.F., and Chhaparwall, B.C. 1974. A rare homozygous form of phosphohexose isomerase. Am. J. Hum. Genet. 26: 474-476.

Papiha, S.S., Roberts, D.F., and Gulati, P.D. 1976. Some erythrocyte enzyme and serum protein system in two communities of North-west India. Hum. Biol. 48: 323-336.

Papiha, S.S. Roberts, D.F. Mukerjee, D.P., Singh, S.D., and Malhotra, M. 1978. A genetic survey in the Bhil tribe of Madhya Pradesh Central India. Am. J. Phys. Anthropol. 49: 179-186.

Papiha, S.S., Chahal, S.M.S., Roberts, D.F., and Singh, I.P. 1980. Genetic studies among Kanets and Kolis of Kinnaur district in Himachal Pradesh, India. Am. J. Phys. Anthropol. 53: 275283

Papiha, S.S., Roberts, D.F., Shah, K.C., and Shah, A.C. 1981. A genetic study of some Gujarat populations. Acta Anthropogenetica 5: 23-40.

Ramesh, A., Murty, J.S., and Blake, N.M. 1979. Genetic studies on the Kolanis, or Andhra Pradesh, India. Hum. Hered. 29: 147-153.

Ramesh, A., Blake, N.M., Vijayarkumar, M., and Murty, J.S. 1980. Genetic studies on the Cherichu tribe of Andhra Pradesh, India. Hum. Hered, 30: 291-298.

Rao, P.M., Blake, N.M., and Veerraju, P. 1978. Genetic studies on the Savara and Jatapu tribes of Andhra Pradesh, India. Hum. Hered. 28: 123-131.

Roberts, D.F. Papiha, S.S., Rao, G.N., Habcebullah, C.M., Kumar, N., and Murty, K.J.R. 1980. A genetic study of some Andhra Pradesh population. Ann. Hum. Biol. 7: 199-212.

Saha, N., Kirk, R.L., Shanbhag, S., Joshi, S.H., and Bhatia, H.M. 1974. Genetic studies among Kadar of Kerala. Hum. Hered. 24: 198-218.

Vol. 29, No. 2, 1984 
Saha, N., Kirk, R.L., Shanbhag, S., Joshi, S.R., and Bhatia, H.M. 1976. Population genetics studies in Kerala and the Niegiris (South west India). Hum. Hered. 20: 175-197.

Sanpitak, N., Supalert, Y., Chayatimonkul, L., and Flatz, G. 1973. Combined erythrocyte phosphohexose isomerase and glucose and phosphate dehydrogenase deficiency. Hum. Hered. 23: 83-87.

Shinoda, T. 1970. Inherited variations in red cell phosphoglucomutase isomerase among Japanese. Jap. J. Hum. Genet. 15: 159-165

Tariverdian, G., Arnold, H., Bluhm, K.G., Lenkeit, U., und Löhr, G.W. 1970. Zur formalgenetik der Phosphoglucoseisomerase. Untersuchung, einer sippe mit PGI defizienz. Humangenetik 10: $218-223$

Tilley, B.E., Gracy, R.W., and Welch, S.G. 1974. A point mutation increasing the stability of human phosphoglucose isomerase. J. Biol. Chem. 249: 4571-4578.

Welch, S.G. 1971. Qualitative and quantitative variants of human phosphoglucose isomerase. Hum. Hered. 21: 467-477. 